IFN Working Paper No. 892, 2011

\title{
Nuclear Capacity Auctions
}

\section{Sven-Olof Fridolfsson and Thomas Tangerås}




\title{
Nuclear capacity auctions
}

\author{
by \\ Sven-Olof Fridolfsson \\ (sven-olof.fridolfsson@ifn.se) \\ and \\ Thomas P. Tangerås* \\ (thomas.tangeras@ifn.se) \\ Research Institute of Industrial Economics (IFN) \\ Box 55665, 10215 Stockholm, Sweden
}

January 31, 2012

\begin{abstract}
We propose nuclear capacity auctions as a means to improve the incentives for investing in nuclear power. A properly designed auction $(i)$ allocates the license to the most efficient bidder; (ii) sells the license if and only if new nuclear power is socially optimal. In particular, capacity auctions open the market for large-scale entry by outside firms. Requiring licensees to sell a share of capacity as virtual power plant contracts increases auction efficiency by softening incumbent producers' incentive to bid for market power. Our motivating example is Sweden's recent decision to allow new nuclear power to replace old reactors.
\end{abstract}

Keywords: Capacity auctions; investments; market power; nuclear power; virtual power plants.

JEL Codes: D44; L12; Q48.

${ }^{*}$ Corresponding author. 


\section{Introduction}

The decision of the Swedish Parliament in 2010 to open up for new nuclear power marks a uturn in the country's nuclear policy. The previous 30 years the official policy had been full abandonment. The reactors were to be phased out as fast as the energy system permitted, bearing in mind the consequences for employment and economic welfare. The fundamental role played by nuclear power in Swedish electricity supply - it accounts for some $45 \%$ of annual production - can help explain why only two out of the twelve reactors actually have been shut down.

In light of the nuclear policy reversal, the main question is how nuclear investment, if socially desirable, will come about. One approach would be to regulate the amount of nuclear power. Regulation is problematic because the investment cost, hence optimal capacity, is unknown to the central planner. A main argument behind Swedish liberalization was to encourage marketbased investment decisions. In a liberalized electricity market producers invest in capacity if and only if privately profitable. Three of the largest players in the Nordic electricity market, E.ON, Fortum and Vattenfall, jointly decide how much to invest in Swedish nuclear because they share the ownership of all three nuclear plants. Joint ownership implies a risk that the investors internalize a large share of the subsequent profit loss on current production resulting from higher nuclear capacity and lower electricity prices. Exercise of long-run market power would lead to under-investment and excessive electricity prices.

Greenfield investments or increased imports curtail market power in a market with free entry. However, the Swedish electricity market is characterized by significant entry barriers. For example, transmission bottlenecks limit imports and are under monopoly control of the Swedish Transmission System Operator, Svenska Kraftnät. The new Swedish legislation does open up for large-scale entry of nuclear power. In practice, the incumbent producers control if and when to phase in new nuclear power and by whom. By law, there will be no more than ten new reactors, and only at the three current sites. The sites are owned by the incumbent nuclear producers. Finally, no new reactor can be set into operation until an old one shuts down.

While important to curb market power, entry is associated with potential welfare gains even in a well-functioning market: successful entry occurs if and only if the challengers are more efficient than the incumbents, either in terms of lower investment costs or because they 
produce more efficiently. Lowering entry barriers is thus valuable independently of whether the incumbents wield market power. This paper proposes and discusses one specific method to open up for large-scale entry into the Swedish electricity market: capacity auctions for new nuclear reactors.

In a nuclear capacity auction, the seller, say a government agency, auctions off a license to build and operate a nuclear reactor to the highest bidder. If properly specified, the auction allocates the license to the most efficient bidder - the one with the lowest investment cost. By specifying an appropriate threshold, the reserve price, the seller ensures that the license is sold if and only if it is socially optimal to build the reactor. The auction is likely to produce a more efficient result the larger is the set of serious ${ }^{1}$ bidders because the expected minimum investment cost is lower, and bidding competition is fiercer the more bidders are active in the auction. ${ }^{2}$ As an added benefit, fine-tuning the auction is less important the higher the number of bidders (Bulow and Klemperer, 1996):

Recommendation 1: Encourage as many serious bidders as possible to participate in the nuclear capacity auction.

Entrants both account for the expected operating profit and the investment cost in their bidding. As the auction is a license to replace old nuclear power by new, bidders should ideally account for the opportunity cost of the license, namely the expected operating profit of the old facility. This opportunity cost is private information to the incumbent who might have an incentive to conceal it. ${ }^{3}$ A straightforward way to internalize the opportunity cost is to allow the incumbent producers to participate in the auction. And possibly the incumbents have a lower investment cost than all other bidders:

Recommendation 2: Incumbent producers should not as a rule be denied to participate in the nuclear capacity auction.

Nuclear investments affect electricity prices owing to changes in marginal production cost or because new reactors have a different capacity than the old ones. Investment decisions risk

\footnotetext{
${ }^{1}$ A serious bidder here refers to an investor or set of investors with the competence and financial resources to build or subcontract a nuclear reactor and operate it according to safety and market regulations.

2 The pro-competitive effects of increasing bidder participation are well-known and hold under general circumstances; see e.g. Milgrom (2004).

${ }^{3}$ The presence of an opportunity cost of selling the license, which, moreover, might be private information to one of the bidders, is a problem we have not encountered in the auction literature. Deriving the optimal auction under these circumstances is an area for future research.
} 
being distorted to the extent producers fail to account for the effect on consumer surplus when bidding for nuclear power. A bidding consortium of producers and industrial consumers would partly internalize consumer surplus and align consumer and producer interests in the bidding process:

Recommendation 3: Encourage the participation of the energy intensive industry in bidding consortia for nuclear capacity.

Despite several attempts, it has proven impossible to convince the incumbent producers in Sweden to voluntarily dissolve joint ownership of their nuclear facilities. The capacity auction offers an opportunity to restructure the electricity market insofar as no general rule stipulates that new nuclear power should have the same ownership structure as the old one. On the contrary, joint ownership exacerbates the underinvestment problem because the perceived opportunity cost of replacing the old facility by a larger one increases:

Recommendation 4: Bidding consortia should not contain more than one producer each.

Market concentration, price insensitive demand and limited import substitution render electricity markets particularly susceptible to the exercise of short-run market power (Joskow, 2008). If market power is valuable, incumbent producers are willing to pay a premium on the license to protect themselves from entry. The premium could be so high that an incumbent wins the license even if at a cost disadvantage to an entrant. In this case competition is weaker than necessary and the most efficient producer does not run the new facility - if built at all:

Recommendation 5: Require of the owners of new nuclear capacity that they sell a share of their capacity as virtual power plant contracts.

A virtual power plant (VPP) contract is an option which gives the holder the right to purchase the contracted amount of electricity from the producer at marginal production cost. An owner forced to sell capacity as VPP contracts effectively delegates the production decision to those who hold the contracts. An incumbent is willing to pay a premium for the license because ownership allows to reduce production in the new facility and uphold the profit on other production. An incumbent lacking control over the new facility's output is no longer willing to pay a premium for the license. Thus, VPP contracts restore bidding competition and increase final output under imperfect short-run competition. 
The Swedish government levies a number of taxes on nuclear power, including a tax on installed capacity. Raising the capacity tax is politically tempting because it causes no shortterm distortions in the economy. In the long run, anticipated tax expropriation has detrimental effects on investments. We propose long-term supply contracts as a potential solution to tax expropriation. Assume that the owner of a nuclear license prior to setting the plant into operation sells long-term supply contracts which give the holder the option to purchase electricity at marginal production cost. The revenue can be used to finance the plant's construction, thereby reducing capital costs. In addition, the contracts offer investors protection against tax expropriation because operating profit is zero on contracted production. Energy intensive industries hedging their electricity consumption would be typical buyers of long-term supply contracts. Tax expropriation is limited to the extent taxing large industrial consumers is politically more difficult than taxing producers. To preserve investment incentives it would even be in the government's self interest to protect investors against tax expropriation:

Recommendation 6: Encourage the owners of nuclear licenses to sell a share of production as long-term supply contracts for electric power.

We have framed our analysis of nuclear capacity auctions in the legal context of new nuclear power in Sweden, but it should be obvious that our results apply more generally. For most countries, scale economies render a small number of nuclear reactors commercially viable and only at a limited number of sites. Every policy maker concerned with economic welfare faces the question how many nuclear licenses to award and to whom, just as in the Swedish case. Short-run market power is a common feature of electricity wholesale markets. Incumbents bidding to preserve market power therefore constitutes a general risk in nuclear capacity auctions. The short-run incentive to tax assets after the investment cost is sunk is a general phenomenon and not related to nuclear power in particular.

Our finding that consumer participation in bidding consortia increases auction efficiency is novel as far as we understand. The standard solution would be to account for consumer effects in the reserve price. One problem with modifying the reserve price is that consumer surplus is unobservable to the seller. Consumer participation promises to be a general solution because most wholesale electricity markets feature large industrial consumers purchasing electricity. Our result that VPP contracts can mitigate the incentive to bid for market power appears to be new. Ausubel and Cramton (2010b) discuss VPP auctions at length without mentioning them 
in relation to capacity auctions. The usual approach in the auction literature is to modify the auction itself to account for such externalities; see e.g. Jehiel et al. (1996). Finally, long-term supply contracts appears to be a novel idea as a potential solution to tax expropriation.

\section{Market description}

Denmark, Finland, Norway and Sweden form the integrated Nordic electricity market. ${ }^{4}$ A striking feature of this market is its reliance on hydro power; see Table 1. Hydro power represents half of installed capacity and is located predominantly in Norway and Sweden. Finnish and Swedish nuclear power represent ten percent of total generation capacity. Thermal capacity other than nuclear power (mainly combined heat and power) accounts for roughly thirty percent of capacity. Only Denmark and Sweden have invested significant amounts in wind power.

Table 1: Generation capacity (GW) in the Nordic market 2010

\begin{tabular}{|l|c|c|c|c|c|}
\hline & Denmark & Finland & Norway & Sweden & Total \\
\hline Hydro power & - & 3,1 & 29,9 & 16,2 & 49,2 \\
\hline Nuclear power & - & 2,7 & 0 & 9,1 & 11,8 \\
\hline Other thermal power & 9,7 & 10,9 & 1,1 & 8,2 & 29,9 \\
\hline Wind power & 3,8 & 0,2 & 0,4 & 2,2 & 6,6 \\
\hline Total & 13,5 & 16,9 & 31,4 & 35,7 & 97,5 \\
\hline
\end{tabular}

Source: NordREG (2011)

The first large scale nuclear power plant in the Nordic region was Oskarshamn in Sweden, whose first reactor started to deliver electricity in 1972. Over the course of the following 13 years, 15 additional reactors were put into operation in Finland and Sweden. In 1985, when the third reactor in Forsmark was connected to the grid, the tide had already turned against nuclear power in Sweden. As a consequence of the Three Mile Island accident in 1979, the official Swedish policy from 1980 and onwards was to abandon nuclear power altogether. ${ }^{5}$ Barsebäck nuclear plant was subsequently shut down, the first reactor in 1999 and the second in 2005. Finland, on the other hand, has remained positive to nuclear power during this time and has instead decided to expand nuclear production. A third reactor is under construction at

\footnotetext{
${ }^{4}$ In addition, the Nordic market is interconnected with Estonia, Germany, Poland, Russia and The Netherlands.

5 The 1980 Swedish referendum in which a majority of the participants voted against nuclear power is sometimes mentioned as the turning point, but was only a pretext: voters only had the choice between three different variants of no, yes was not an option.
} 
the Olkiluoto site, and the Finnish government has recently authorized the construction of two new reactors.

Table 2: Ownership shares of Nordic nuclear power

\begin{tabular}{|l|c|c|c|c|c|}
\hline & \multicolumn{3}{|c|}{ Sweden } & \multicolumn{2}{c|}{ Finland } \\
\hline & Forsmark & Oskarshamn & Ringhals & Loviisa & Olkiluoto \\
\hline E.ON & 10 & 55 & 30 & - & - \\
\hline Fortum & 22 & 45 & - & 100 & 27 \\
\hline Vattenfall & 66 & & 70 & - & - \\
\hline Pohjolan Voima & - & & - & - & 57 \\
\hline Capacity - MW & $3138(3)$ & $2311(3)$ & $3702(4)$ & $1156(2)$ & $1540(2)$ \\
\hline
\end{tabular}

Source: The websites of the respective nuclear plants

Table 2 identifies the owners of the five nuclear plants currently operating in the Nordic market, along with the net capacity of each plant (the number of reactors is in parenthesis). ${ }^{6}$ All three Swedish plants are jointly owned by two or more large generation companies. This is not the case in Finland. The largest Finnish generation company, Fortum, owns Loviisa on its own. Olkiluoto is jointly owned by Fortum and the energy intensive industry: Pohjolan Voima is controlled by the pulp and paper manufacturers United Paper Mills and Stora Enso.

\section{Figure 1: Nuclear capacity utilization Sweden versus Finland 1971-2009}

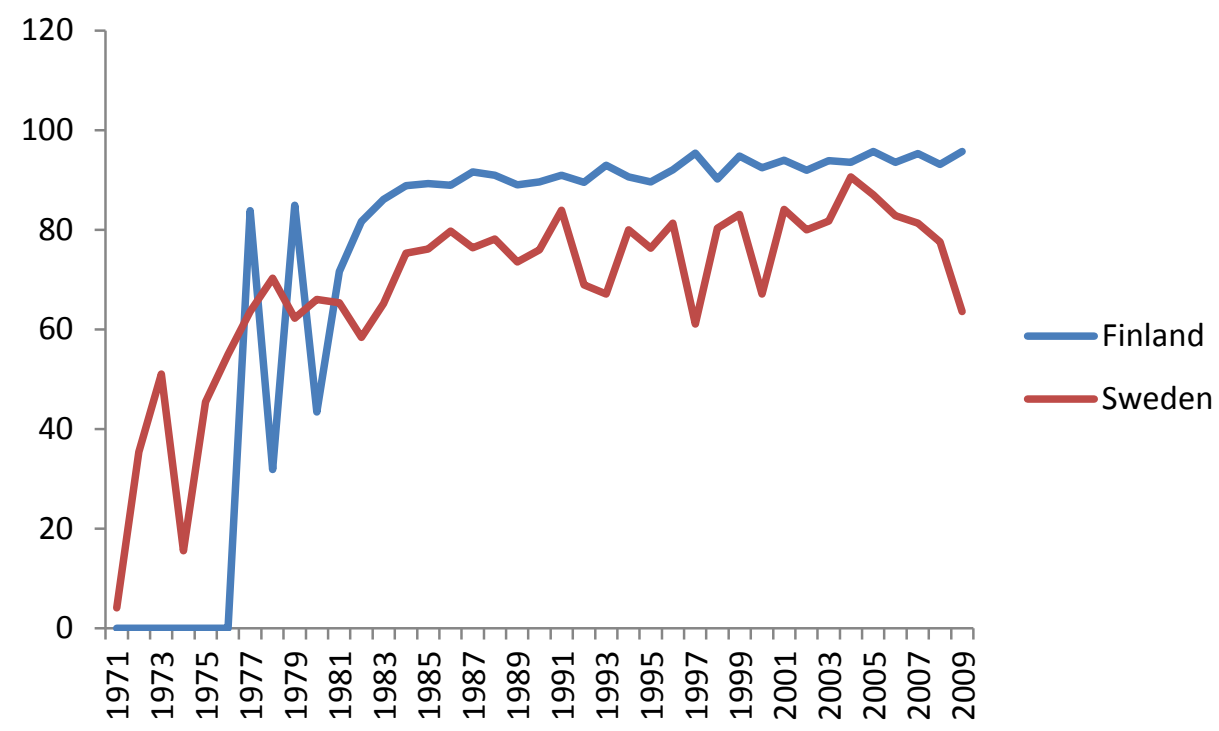

Source: IAE- PRIS database

\footnotetext{
${ }^{6}$ A few smaller companies own minority shares of Forsmark and Olkiluoto. Therefore, the shares do not add up to 100 for these two plants.
} 
Capacity utilization in Swedish nuclear power plants has been lower than in their Finnish counterparts every year since 1981. Figure 1 displays annual capacity utilization averaged over the four Finnish and ten Swedish reactors (excluding Barsebäck). The volatility over the first ten years stems from the fact that most reactors were phased-in during that period. Interestingly, the relative under-performance of Swedish nuclear power plants predates market liberalization in 1996.

75 percent of the electricity production in the four Nordic countries is traded on the common power exchange, Nord Pool. Bilateral contracts between producers, retailers and end consumers make up the rest. More than 200 producers sell their electricity on Nord Pool, and no single producer owns more than 20 percent of total generation capacity (NordREG, 2011). Yet, market concentration is higher than these numbers seem to suggest. Bottlenecks in the transmission grid regularly divide the Nordic market into geographically concentrated markets, so-called price areas. Market concentration may be significant within the price areas because the areas often are delimited by national borders and the four incumbent producers Dong (Denmark), Fortum (Finland), Statkraft (Norway) and Vattenfall (Sweden) possess dominant positions in their home countries. The only new major entrant is the German power company E.ON which acquired Sydkraft in 2001 and thereby took over Sydkraft's strong position in southern Sweden. Joint ownership of generation capacity by multiple producers, most notably nuclear power, adds to market concentration.

\section{The incentives for investing in nuclear power}

In a competitive market, all firms take the price as given and increase production until the cost of producing one additional unit of the good - the short-run marginal cost-equals the price. By contrast, a firm exercising market power takes into account that increased production leads to lower prices. The value of an increase in production - the marginal revenue - is therefore lower than the price. Any profit-maximizing firm can be expected to exercise market power, although doing so is more difficult when markets become more competitive.

In the long run, the owners must decide how much to invest in new production capacity. A company with unilateral market power faces the same trade off in its investment decision as in the production decision: higher capacity will increase profits as output increases, but the profitability of installed generation capacity drops due to falling prices. 


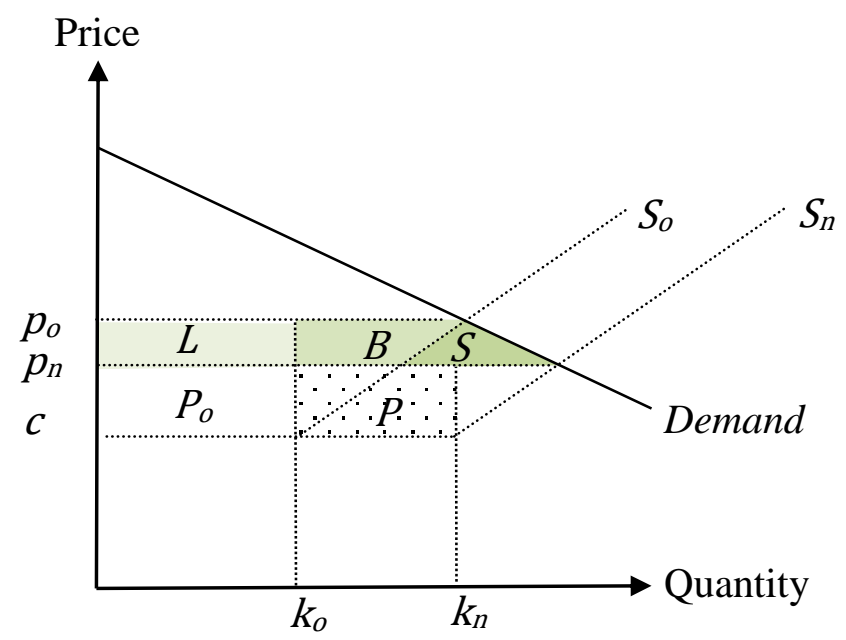

Figure 2 illustrates the trade-off between price and capacity. A nuclear power plant produces base load electricity up to its capacity $k_{o}$ at constant marginal cost $c$. Additional consumption is covered by increasingly costly peak load production. Under the assumption that the market is competitive in the short run, supply is given by the short-run marginal cost curve $S_{o}$. The corresponding market-clearing price equals $p_{o}$. The operating profit of the nuclear plant equals $\pi_{o}=\left(p_{o}-c\right) k_{o}$. Assume that the nuclear owner plans to expand capacity from $k_{o}$ to $k_{n}$. Supply shifts outward to $S_{n}$, and the price falls to $p_{n}$. Operating profit in the new plant equals $\pi_{n}=\left(p_{n}-c\right) k_{n}$. The dotted area $P$ represents the profit increase from the additional capacity: $\left(p_{n}-c\right)\left(k_{n}-k_{o}\right)$. The light shaded area $L$ is the profit loss the incumbent suffers on installed nuclear capacity resulting from the lower electricity price: $\left(p_{o}-p_{n}\right) k_{o}$. The white area $P_{o}=\left(p_{n}-c\right) k_{o}$ represents the part of profit which is constant irrespective of whether production takes place in the old or new facility. Demand here is sufficiently price sensitive that capacity expansion dominates the profit loss on installed capacity: $P>L$. Yet, the investment is unprofitable if the increase in operating profit is insufficient to cover the incumbent's investment cost $F_{I}$, i.e. $P-L<F_{I}$. The investment has consequences beyond the profitability of nuclear power. The price reduction from $p_{o}$ to $p_{n}$ inflicts a loss on peak load production equal to the darker area $B$ in Figure 2. Consumer surplus, on the other hand, increases by $L+B+S$. The terms $L+B$ represent pure redistribution from producers to consumers and therefore have no welfare effect.

The net welfare gain/loss equals the net increase in consumer surplus, $L+S$, plus the change in nuclear operating profit, $P-L$, less the investment cost, $F_{I}$. Market power generally leads to underinvestment because the owners of the nuclear plant do not internalize the positive 
effect on consumer surplus of the capacity expansion. In particular, investments by the incumbent are socially desirable, but privately unprofitable if

$$
P-L<F_{I}<P+S
$$

Underinvestment is an even more serious problem in case nuclear power is jointly owned by the producers. Under joint ownership at least part of the profit loss $B$ on peak load production would be internalized in the investment decision.

In a market without entry barriers, the ability to exercise long-run market power is limited by potential entry. An entrant who plans to build a nuclear facility with capacity $k_{n}-k_{o}$ internalizes the increase $P$ in producer surplus, but not the profit loss $L$. Entry is profitable if $P$ is large enough to cover the entrant's investment cost, i.e. $P>F_{E}$. Note also that the mere threat of entry may be enough to induce investments. By investing $k_{n}-k_{o}$ in additional capacity, the incumbent at least gains the additional profit $P$ and does not only suffer the loss L. Thus, a stable market structure (few entries and exits) does not constitute prima facie evidence of an imperfectly competitive market.

Public opposition to nuclear power and to the industrial development of unexplored river basins have so far presented significant entry barriers to the development of new nuclear and large scale hydro production in Sweden. Furthermore, import competition is limited by the capacity of the international transmission interconnections, which are under monopoly control of the Swedish Transmission System Operator, Svenska Kraftnät. Entry barriers suggest strong possibilities for exercising long-run market power in the Swedish electricity market.

Typical measures of market power are based on the wedge between price and marginal cost. In electricity markets which rely mainly on thermal energy, reliable short-run marginal cost curves can be constructed on the basis of engineering data over the individual power plants. Thus, short-run market performance can be calculated by comparing price and estimated marginal cost (Wolfram, 1999; Borenstein et al., 2002). The study of long-run market performance is much more difficult because it is necessary to estimate the competitive returns to capital in order to estimate long-run marginal cost. Estimates based upon historical data are not useful, either because historical returns reflect market power themselves or because the returns reflect regulatory policy in case the returns are estimated on pre-liberalization data. Furthermore, entry barriers stemming from political decisions to limit large scale hydro and nuclear investments have most likely affected capital returns in the Swedish market, making it 
very difficult to disentangle any effects of market power. These challenges probably explain the lack of empirical research on long-run market power in the Swedish electricity market and also indicates why it may be particularly tempting to exercise long-run market power.

Entry generates potential welfare even absent long-run market power problems. Entry occurs and is successful in a competitive market if and only if the entrants are more efficient than the incumbents, either in terms of lower investment costs $\left(F_{E}<F_{I}\right)$ or because they produce more efficiently. Not least the relatively low capacity utilization in Swedish nuclear power plants (see Figure 1) suggests a potential for improved productive efficiency.

The Swedish Parliamentary decision in 2010 to allow the replacement of the old reactors by new ones opens up a possibility to achieve a more efficient market structure, with lower market concentration and more efficient producers. To select among the prospective owners, we propose an auction for the license to build and operate nuclear power, a so-called capacity auction. The purpose of this auction is to select the most efficient producers and to allow investment if and only if socially desirable (in a partial equilibrium sense).

\section{A nuclear capacity auction}

The parliamentary decision to allow new nuclear power places firm restrictions on the number of reactors, where they should be built and when they should be put into operation. The first legal restriction is that each new reactor must replace an old one.

Revisit Figure 2 and consider a set of $J$ potential entrants bidding for the license to replace the old reactor with capacity $k_{o}$ by a new reactor with larger capacity $k_{n}$ and marginal production $\operatorname{cost} c$. If each bidder would run the facility competitively, they all gain the same operating profit $\pi_{n}=P_{o}+P$, where $P$ is the operating profit stemming from the capacity expansion and $P_{o}$ is the profit in the old plant at the new price $p_{n}$. Bidder $j \in J$ has investment $\operatorname{cost} F_{j}$ and therefore values the license (gross of any payment) at $\pi_{n}-F_{j}$.

Assume the license is sold by means of a Vickrey auction: it is sold if and only if at least one bid exceeds a threshold, the reserve price. The license goes to the highest bidder at the price of the second highest bid or the reserve price, whichever the highest. As is well known, bidding one's true valuation is a dominating strategy in the Vickrey auction. If sold, the license goes to the entrant with the lowest investment cost $F_{E}$. The entrants' bids neither 
account for the consumer surplus increase $L+S$, nor the profit loss $\pi_{o}=L+P_{o}$ (see Figure 2) stemming from the shutdown of the old plant. The reserve price

$$
b^{*}=P_{o}-S
$$

ensures that the investment is undertaken if and only if socially desirable, as $\pi_{n}-F_{E} \geq b^{*}$ is equivalent to $P+S \geq F_{E}$. One may think of $b^{*}$ as the social opportunity cost of keeping the old plant operative. Typically, the reserve price is different from zero. If, for example, the increase in consumer surplus is higher than the profit loss in the old plant $\left(S>P_{o}\right)$ it could be optimal to subsidize the bidders, i.e. some negative bids should be accepted. The official policy of the Swedish government is however that no new nuclear power should be subsidized. This requirement translates into a non-negative reserve price in this setting. A second problem is that $b^{*}$ is unobservable to the seller, not least because the reserve price must be evaluated at the future expected price $p_{n}$. To incorporate these constraints, we assume that the reserve price is zero, and both $P_{o}$ and $S$ are non-contractible. ${ }^{7}$ Still, this simplified auction produces an optimal result when private and social incentives are aligned. That is, if investments are privately profitable to at least one bidder $\left(F_{E} \leq \pi_{n}=P+P_{o}\right)$ and investments are socially desirable $\left(F_{E} \leq P+S\right)$ :

$$
F_{E} \leq P+\min \left\{P_{o} ; S\right\}
$$

or if investments are privately $\left(F_{E}>P+P_{o}\right)$ as well as socially $\left(F_{E}>P+S\right)$ unprofitable:

$$
F_{E}>P+\max \left\{P_{o} ; S\right\}
$$

The simple auction is likely to produce a socially desirable result the larger is the set of bidders because the expected minimum investment cost is lower and bidding competition is fiercer the more bidders are active in the auction.

Recommendation 1: Encourage as many serious bidders as possible to participate in the nuclear capacity auction.

By serious bidders we mean investors who are capable of building/contracting and operating a nuclear reactor according to safety and market regulations. As it is costly for bidders to prepare their bids, we expect most participants in the auction to be serious. Still, for any given

\footnotetext{
${ }^{7}$ Naturally, the reserve price could build on estimates of the two.
} 
number of bidders, there are circumstances under which the simplified auction leads to distortions. If the social opportunity cost of investing in nuclear power is positive $\left(P_{o}>S\right)$, overinvestment occurs if

$$
P+S<F_{E} \leq P+P_{o}
$$

because then the investment cost is too high relative to the welfare gains, but at least one bidder has a positive valuation of the license.

A simple way of eliminating overinvestment is to allow the incumbent to participate in the auction. Let the incumbent have the option of building the new plant or keeping the old one contingent on winning the license. The incumbent's valuation is $\max \left\{\pi_{n}-F_{I} ; \pi_{o}\right\}$ gross of the license fee. In this case, the new reactor is built if and only $\min \left\{F_{E} ; F_{I}\right\} \leq \pi_{n}-\pi_{o}=\mathrm{P}-$ $\mathrm{L}^{8}$ If the incumbent participates in the auction, there will be overinvestment if and only if

$$
P+S<\min \left\{F_{E} ; \mathrm{F}_{\mathrm{I}}\right\} \leq P-L,
$$

which is impossible because the increase in consumer surplus $S$ and the loss in operating profit $L$ are both positive.

Recommendation 2: Incumbent producers should not as a rule be denied to participate in the nuclear capacity auction.

There are two reasons for allowing the incumbent to participate in the auction. First, the incumbent may have a lower investment cost than all other bidders $\left(F_{I}<F_{E}\right)$. Second, the incumbent internalizes the opportunity cost of the profit of the old nuclear plant in its decision. Internalizing a profit loss amounts to account for the value of market power in the auction and, as argued in the previous section, market power leads to a risk of underinvestment. ${ }^{9}$ This happens in the auction with a participating incumbent if and only if

$$
P-L<\min \left\{F_{E} ; \mathrm{F}_{\mathrm{I}}\right\}<P+S \text {. }
$$

\footnotetext{
8 If the condition holds, the new reactor is built by the incumbent (if $F_{I} \leq F_{E}$ ) or by the most efficient entrant (if $\mathrm{F}_{\mathrm{E}} \leq \mathrm{F}_{\mathrm{I}}$ ). Otherwise the new reactor is not built, as the incumbent wins the license and does not exercise the option to build.

${ }^{9}$ In the model, underinvestment occurs if an old reactor is maintained in operation although it should have been replaced by a new one. In reality, underinvestment could mean that the new plant is taken into operation later than what it socially optimal. Our arguments apply even to the problem of delayed investments.
} 
In the capacity auction, potential entrants challenge the incumbent for the license to build new nuclear power. Competition implies that the underinvestment problem is smaller in the auction than in the default situation where the incumbent controls the investment, compare (2) with (1). A second difference is that the incumbent must pay the seller a license fee for the option to exercise market power. Effectively, the auction transfers some of the proceeds of market power back to society. Note also that underinvestment not necessarily constitutes a grave problem. The Vickrey auction with reserve price $b^{*}$ generally does not maximize expected seller revenue. By increasing the reserve price above $b^{*}$, the seller extracts higher expected rents from the bidders at the risk of not selling the license; see Myerson (1981) for the original treatment. Doing so could be efficient in a second-best sense: even a benevolent social planner would exercise market power in the auction if the purpose was to increase expected government revenue and thereby reduce tax distortions elsewhere in the economy.

If underinvestment is a real concern, the seller would prefer the bidders to internalize some of the consumer surplus generated by the investment. One possibility is to allow the energy intensive industry to join generating companies in a bidding consortium. Industrial consumers value nuclear power investments according to the difference between their full willingness to pay for electricity and the production and investment costs. Generating companies value investments according to the marginal consumer's willingness to pay, i.e. the price relative to the production and investment costs. Thus, the least-cost bidding consortium values the investment at $\pi_{n}-F_{E}+\alpha(L+B+S)$, where $\alpha$ depends on consumer ownership share, the perceived probability that the nuclear power plant is not built and the demand for electricity. If all bidders including the incumbent have formed symmetric bidder consortia, the new reactor will be built by the least-cost consortium subject to

$$
\min \left\{F_{E} ; \mathrm{F}_{\mathrm{I}}\right\} \leq \pi_{\mathrm{n}}-\pi_{o}+\alpha(L+B+S)=P-L+\alpha(L+B+S) .
$$

In this (very parametric) case, the private and social preferences are perfectly aligned if

$$
\alpha=\frac{L+S}{L+B+S}
$$

The energy intensive industry is valuable as owners of nuclear power plants because they internalize the consumer surplus and not only the operating profit. The Finnish nuclear power plant Olkiluoto is an example of joint ownership between generation companies and industrial consumers; see Section 2. 
Recommendation 3: Encourage the participation of the energy intensive industry in bidding consortia for nuclear power.

The value of including industrial consumers, measured by $\alpha$, increases when the effect on consumer surplus of the investment, measured by $L+S$, is stronger. Joint ownership of production facilities implies that nuclear owners internalize parts of the profit loss $B$ on peak load production (see Figure 2) in the decision to invest in additional nuclear capacity. From a welfare viewpoint it is not necessary to internalize $B$ as it constitutes pure redistribution from peak load producers to consumers. Joint ownership on the contrary exacerbates the underinvestment problem because the perceived opportunity cost of replacing the old facility by a larger one increases.

Recommendation 4: Bidding consortia should not contain more than one producer each.

Producers may prefer to jointly own nuclear production for reasons other than the desire to internalize profit losses. Joint ownership could represent a risk-sharing mechanism in case of unexpected break-downs. But joint ownership could equally well aggregate risk. This happens in case of unlimited liability and the damage claims following a serious accident wipe out all owners. Other solutions than joint ownership appear superior in handling risks. A common solution is nuclear pools wherein a larger set of producers shoulder the financial burden of a nuclear disaster. Joint ownership could also be motivated by the substantial capital requirements of constructing a nuclear reactor. The current nuclear plants were built prior to the liberalization of capital markets when access to capital was a real constraint. Raising capital through joint ownership among producers is probably less important today, as capital is supplied in a global market. In addition, investors have the opportunity of selling supply contracts to finance construction. Joint ownership with the industry represents a (very) long term supply contract, for example. Either way, there are examples of new reactors being built without the involvement of multiple generation companies as owners, one of them is the Olkiluoto plant in Finland.

\subsection{Replacement of old facilities}

The new Swedish legislation states that replacement reactors are allowed exclusively at the three sites, Forsmark, Oskarshalm and Ringhals, where the ten current active reactors are located. Barsebäck, the fourth site, is excluded. Moreover, a new reactor cannot be set into operation until an old one shuts down. The owners of the current nuclear facilities even own 
the ground the plants are built on, so the two pieces of legislation effectively delegate to the incumbents the choice if and when to phase-in the replacement reactors.

The incentive to replace old reactors by new ones depends crucially on whether the incumbent owns the replacement reactor or not. Revisit Figure 2 and assume that electricity is competitively supplied in the short run. The current nuclear facility supplies its full capacity $k_{o}$ at the market-clearing price $p_{o}$ with operating profit $\pi_{o}=\left(p_{o}-c\right) k_{o}$ to the incumbent. The new reactor has a higher capacity, $k_{n}$, and generates operating profit $\pi_{n}=\left(p_{n}-c\right) k_{n}$ to the owner, at the lower market-clearing price $p_{n}$. By assumption, the value $P$ of additional capacity is higher than the profit loss $L$ on the old facility so that nuclear operating profit increases with the investment: $\pi_{n}-\pi_{o}=P-L>0$. Net consumer surplus increases by the three areas $L+B+S$ in the figure because of the lower price $p_{n}<p_{o}$.

An incumbent who owns even the replacement reactor will replace the old one as soon as the new one becomes operational because $\pi_{n}>\pi_{o}$ and the investment cost $F_{I}$ is sunk. If, on the other hand, a competitor has won the license to build the replacement reactor, the incumbent has no incentive to shut down the old reactor because its opportunity cost is zero: $\pi_{o}>0$. The rational entrant, expecting that the incumbent will refuse to shut down a profitable plant, is not willing to bid anything for the capacity license. ${ }^{10}$ Thus, delegating to the incumbent the option of shutting down may undermine the entire auction. A social cost arises because of potential underinvestment and because the bidder with the lowest investment cost does not necessarily build the new facility.

The three current nuclear sites probably represent essential facilities from a competition policy viewpoint. If so, current owners could legally be forced to relinquish control of their sites, thereby enabling entrants to build the new reactors. In exchange, the incumbents would have a legal right to a reasonable compensation. So assume that the entrant is under contractual obligation to remunerate the incumbent $C \geq 0$ for the license to build and operate the replacement reactor. Entrant $J$ 's valuation of the license falls to $\pi_{n}-F_{J}-C$ and the incumbent's valuation falls proportionally to $\max \left\{\pi_{n}-F_{I} ; \pi_{o}\right\}-C$ because an incumbent who wins the auction foregoes the compensation $C$. Provided subsidies are forbidden (bids must be positive), $J$ 's dominating strategy is to bid $\max \left\{\pi_{n}-F_{J}-C ; 0\right\}$ and the incumbent's

\footnotetext{
${ }^{10}$ In reality it is probably costly delays which erode the entrant's expected profit.
} 
dominating strategy is to bid $\max \left\{\pi_{n}-F_{I}-C ; \pi_{o}-C ; 0\right\} .11$ The compensation does not cause any inefficiencies if $C \leq \pi_{o}$ : the bidder with the lowest investment cost undertakes the investment. As before, some under-investment still occurs, namely if condition (1) holds and $F_{I} \leq F_{E}$. Two additional distortions arise in case the compensation is excessive, i.e. $C>\pi_{o}$. If $\pi_{o} \leq \pi_{n}-F_{E}<C$, the value of the new facility exceeds the investments cost of the least-cost entrant, but the compensation is so high that all entrants prefer to stay out of the auction. As a consequence, the license remains in the hands of the incumbent. The first distortion arises if $F_{E}<F_{I}$ and $\pi_{n}-F_{I} \geq \pi_{o}$, because then the incumbent undertakes the investment whereas the new facility should have been built by the least-cost entrant. In the second case, $\pi_{n}-F_{I}<$ $\pi_{o}$, there is no investment at all, although the entrant should have been allowed to build a new reactor.

It is important to avoid over-compensating the incumbent so as not to add additional distortions to the underinvestment problem. Applying the compensation criterion $C \leq \pi_{o}$ is difficult. The incumbent has an incentive to exaggerate the value $\pi_{o}$ of continued production in the old plant to extract rents from the entrant. This is a serious problem of asymmetric information: unless the incumbent wins the auction and does not build the new reactor, it is impossible to verify ex post whether the incumbent has honestly reported his true valuation $\pi_{o}$ because the incumbent is compensated for not continuing production in the old plant. This informational advantage guarantees the incumbent an additional informational rent which may cause distortions in the license auction. A solution ensuring that the compensation does not create additional distortions is to lower the reserve price to $-C$. A negative reserve price implies, however, that it is the seller who may have to compensate the incumbent, which is a problem if the seller also cares about auction revenues or losses. Characterizing the optimal auction is beyond the scope of this paper, so we leave this problem on the note that the optimal auction constitutes a problem of multidimensional asymmetric information requiring the honest revelation of $\left(F_{I} ; \pi_{o}\right)$.

An efficient phase-out of a nuclear reactor requires careful planning because of the increasing maintenance costs associated with keeping an old reactor operating at full capacity and the costs of shutting down the reactor and dismantling it. To avoid supply shortages and excessive electricity prices, the phase-out of the old reactor should be coordinated with the phase-in of

\footnotetext{
${ }^{11}$ Bids equal to zero are for simplicity interpreted as a decision not to participate in the auction, except for the incumbent, Thereby the incumbent acquires the license in case he and all other bidders submit zero bids.
} 
the new one. Owing to lead times in the planning and construction of new reactors, it is difficult to determine with perfect accuracy the exact completion time and when the new reactor will become operational. ${ }^{12}$ Any phase-out plan runs the risk of the replacement not being ready when the old one has to shut down. The replacement of multiple reactors should be spread over time to minimize shortage risk. Two factors suggest that timing is not necessarily a grave problem. First, it is likely that some of the new reactors will be owned by incumbent firms who can more easily coordinate the substitution of old reactors for new ones, although at the risk of distortions for market power reasons as discussed above. Second, delays are less of a problem in an integrated market where reserve capacity is larger. In 2009, the 10 Swedish reactors produced a historical low of $50 \mathrm{TWh}$ electricity. This is roughly equivalent to 8 reactors of average Swedish size (915 MW) operating at $80 \%$ capacity utilization. Effectively, two reactors were at a complete standstill throughout 2009. Yet, the average electricity price was lower in 2009 than in 2008 and 2010, two years with significantly higher nuclear production (61 TWh respective $55 \mathrm{TWh}) .{ }^{13}$ Apparently, the current Nordic market is capable of accommodating significant shortfall of nuclear production.

\subsection{The effects of short-run market power}

This section explores how short-run market power may affect the nuclear capacity auction's performance. Consider Figure 3 where an incumbent initially owns two reactors with joint capacity $k_{1}+k_{2}=k_{o}$. Demand is high enough that the incumbent fully utilizes capacity $k_{o}$ even with market power. Thus, electricity is sold at the competitive price $p_{o}$ (not indicated in the figure) which leaves the incumbent an operating profit of $\pi_{o}=\left(p_{o}-c\right) k_{o}$. Assume now that reactor 2 is shut down and replaced by a larger one, expanding nuclear capacity to $k_{n}$. An incumbent who controls entire capacity $k_{n}$ realizes that it is not profitable to fully utilize capacity, and limits nuclear output expansion to $q^{m}$ where marginal revenue $M R$ equals shortrun marginal production cost $c$. Supply equals $S^{m}$, the price falls to $p^{m}$, nuclear operating profit increases to $\pi^{m}=\left(p^{m}-c\right) q^{m}>\pi_{o}$ and the incumbent's profit net of the investment

\footnotetext{
${ }^{12}$ This is particularly relevant for innovative reactor designs. An illustrative case in point is the construction of the first generation III+ reactor in the world, which started July 2005 at the Finnish Olkiluoto site. The reactor was originally scheduled to become operational in May 2009, but has been severely delayed. By the owner's most recent assessment, Olkiluoto 3 will start producing electricity in 2013.

13 A substantial part of the dip in the electricity price is probably explained by the 2009 economic downturn. Industrial electricity consumption was lower in 2009 than in 2008 and 2010. Admittedly, 2009 does not constitute an ideal year for analyzing supply effects. All numbers are from Swede Energy (2011).
} 
cost $F_{I}$ equals $\pi^{m}-F_{I} \cdot{ }^{14}$ If an entrant wins the license, competition in nuclear production ensues. Each firm ignores the competitor's profit loss of a lower price, so nuclear production is higher, $q^{d}>q^{m}$, and industry profit lower, $\pi^{d}=\left(p^{d}-c\right) q^{d}<\pi^{m}$, under duopoly than monopoly. Absent capacity constraints, each duopolist earns $\pi^{d} / 2$.

\section{Figure 3: Short-run market power}

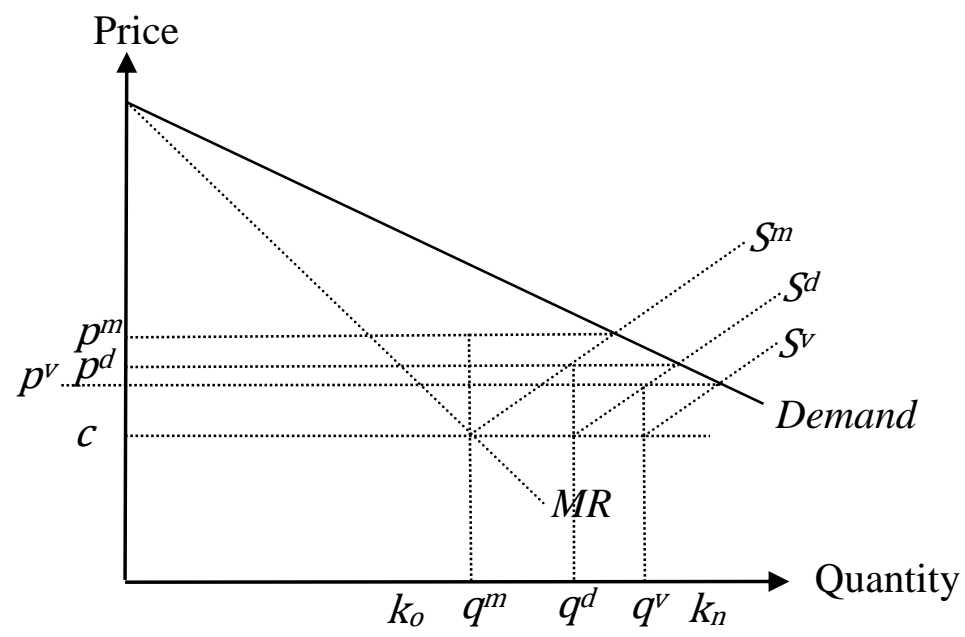

The incumbent's valuation of the license is the difference between winning and losing the auction: $\pi^{m}-F_{I}-\pi^{d} / 2$. Similarly, the entrant's valuation is $\pi^{d} / 2-F_{E}$, where $F_{E}$ is the investment cost. ${ }^{15}$ The auction awards the license to the bidder with the highest valuation, so the incumbent wins the auction if and only if

$$
\underbrace{\pi^{m}-\pi^{d}}_{\text {Market power }}+\underbrace{F_{E}-F_{I}}_{\text {Cost advantage }}>0
$$

The first term in (4) represents the value of market power and is positive because competition depresses industry profit. The value of market power could be so high that the incumbent wins the license even if at a cost disadvantage in building the new facility. The cost to society is two-fold in this case. First, nuclear power is monopolized instead of exposed to competition, which implies a higher than necessary deadweight loss. Second, it is more costly than necessary to build the new plant. Most theoretical approaches modify the auction to account for externalities (e.g. Jehiel et al., 1996). We propose a more practical solution to the problem.

\footnotetext{
${ }^{14}$ For simplicity, we assume that $\pi_{0}<\pi_{m}-F_{I}$, alternatively an incumbent who wins the license is forced replace the reactor. Also, $C=0$ in this section.

${ }^{15}$ To simplify exposition, the participation constraint of the most efficient entrant is assumed to be satisfied, $\pi^{d} /$ $2-F_{E} \geq 0$, so that entry rather than the status quo is the incumbent's relevant alternative to winning the auction.
} 
Assume that whoever wins the contract to build the new facility is forced to sell financial contracts for the full capacity $k_{n}-k_{1}$ of the new reactor in a so-called virtual power plant (VPP) auction. ${ }^{16}$ A VPP contract is a call option which gives the holder the right to purchase the contracted amount of electricity from the producer at marginal cost $c$. A small buyer without market power exercises the option if the expected price of electricity is larger than $c$. The VPP auction de facto partitions the nuclear plant into a subset of smaller plants with marginal cost $c$. Reconsider Figure 3 and assume that all $k_{n}-k_{1}$ VPP contracts have been sold and exercised. Nuclear production increases from $q^{d}$ to $q^{v}$, and the price drops to $p^{v}$. The first observation and a primary justification for VPPs is that they lead to intensified shortrun competition. In addition, VPPs have interesting implications for the auctioning of nuclear capacity licenses which we believe have gone unnoticed until now.

An incumbent who wins the capacity auction retains the operating profit $\pi_{1}^{v}=\left(p^{v}-c\right) q_{1}^{v}$ in reactor 1 , where $q_{1}^{v}=q^{v}-\left(k_{n}-k_{1}\right)$ is the equilibrium production in reactor 1 at price $p^{v}$, pays the investment cost $F_{I}$, and earns $\pi_{2}^{v}=\left(p^{v}-c\right)\left(k_{n}-k_{1}\right)$ from selling the $k_{n}-k_{1}$ VPP contracts of reactor 2 because the value of a single option with strike price $c$ is $p^{v}-c$. If the incumbent loses the auction to an entrant, he earns $\pi_{1}^{v}$ on reactor 1 and nothing else. The incumbent's valuation of the license for the new nuclear plant thus equals

$$
\pi_{1}^{v}+\pi_{2}^{v}-F_{I}-\pi_{1}^{v}=\pi_{2}^{v}-F_{I}
$$

The entrant's valuation is the total income of selling the $k_{n}-k_{1}$ VPP contracts less the investment cost: $\pi_{2}^{v}-F_{E}$. The incumbent wins the auction if and only if

$$
\pi_{2}^{v}-F_{I}>\pi_{2}^{v}-F_{E} \Leftrightarrow \underbrace{F_{E}-F_{I}}_{\text {Cost advantage }}>0
$$

The requirement to sell the full capacity of the new reactor as VPP contracts has eliminated the effect of market power on bidding competition present in (4). Absent VPP contracts, the incumbent is willing to pay extra for maintaining monopoly power because a monopolist owning both plants internalizes the negative market externality by reducing production in the new facility. With mandatory VPP contracts, production in the new facility is instead

\footnotetext{
${ }^{16}$ Ausubel and Cramton (2010b) give a detailed account of VPP auctions. VPP auctions were first used in France in 2001 when the dominant producer EDF was forced to sell nuclear capacity in this manner. In the Nordic market, the Danish producer DONG regularly auctions off $600 \mathrm{MW}$ of its installed capacity in the price area Denmark West (Jutland) where it holds a dominant position; see http://www.nordpoolspot.com/TAS/VPPauction/.
} 
determined by the holders of the VPP contracts. The incumbent thus loses the ability to internalize the market externality and thereby also the willingness to pay a market power premium.

Recommendation 5: The owners of new nuclear capacity should be forced to sell a significant share of their capacity as virtual power plant contracts.

In this particular example, where the whole new capacity $k_{n}-k_{1}$ is sold at the VPP auction and all options are exercised non-strategically, the market externality completely vanishes in the capacity auction. The assumption of a competitive market for VPP contracts is reasonable. Entry costs are small and every buyer can contract on a small volume - there are no returns to scale in running a virtual power plant. The set of potential bidders is large. The ownership of a virtual power plant presents an opportunity for producers not currently active to gain a foothold in the market. Second, VPP contracts allow large industrial consumers the possibility to hedge their electricity consumption. Incumbent producers should probably not be permitted to bid for VPP contracts. They may have a willingness to pay a premium for VPP contracts in order to preserve market power by limiting the amount of VPP options that are actually exercised.

In reality, the contract volume at the VPP auction is likely to be below full capacity $k_{n}-k_{1}$. If so, the incumbent who owns both facilities may exercise market power on the share of capacity which is not sold at the VPP auction. In general, VPP contracts reduce the value of bidding to preserve market power and eliminates this motive in the limit when the entire capacity is sold at the VPP auction.

Why would a producer ever exercise market power by withholding cheap base-load instead of expensive peak-load production? First, some producers have no other option. The Swedish incumbent, Vattenfall, mainly keeps hydro, nuclear and wind power in its Nordic portfolio. Wind power is difficult to control and spilling water is illegal, leaving nuclear power as the only possibility. Second, withholding nuclear power is the cheapest way of exercising market power from time to time. All nuclear reactors must shut down production on a regular basis for maintenance and reloading. In Sweden, this is typically done in the summer or fall. Starting and stopping nuclear reactors are associated with ramping costs. Rather than starting a nuclear reactor and shutting down alternative production, it is cost efficient to prolong the maintenance stops. Such a strategy is particularly profitable in a hydro-nuclear power system 
as in the Nordic market. Hydro power effectively allows the owner to transfer nuclear underproduction from the summer to the winter when prices are higher and demand is more inelastic. Excessive maintenance stops drain hydro facilities of stored water, as hydro replaces nuclear in electricity supply. The lower are the reservoir levels in the fall, the higher are the expected prices in the winter. Finally, it is difficult to detect nuclear market power. Standard measures such as the Lerner index rely on differences between price and marginal production cost. This is a valid approach for peak load production. But nuclear power is base load and therefore usually priced above marginal cost even at competitive equilibrium. Measures based on capacity utilization are also difficult to apply because it is very easy to mask withholding as something else. It is impossible for an outsider to distinguish whether production stands still for security reasons or with the purpose of increasing the electricity price.

Much of the empirical evidence suggests that the Nordic electricity market in fact is quite competitive. Insofar power companies are found to exercise market power, it happens sporadically and only locally when bottlenecks divide the Nordic electricity market into price areas; see Fridolfsson and Tangerås (2009) for a survey of this research. However, all empirical studies of market power in the Nordic electricity market build upon the assumption that nuclear power is competitively supplied. Nobody, except the generation companies, know whether they ever limit nuclear production to uphold a high price.

VPP contracts are designed to alleviate problems associated with the exercise of short-run market power. This does not mean that imposing VPP contracts on the producers is a mistake absent short-run market power. Under perfect competition they simply have no welfare effect besides the direct cost of setting them up. One may also think that VPP contracts are useless if the object for sale is a license to construct a power plant of optional rather than of prespecified size. The incumbent would simply control the maximum amount of VPP contracts by its choice of capacity. Because of fluctuating demand, there will always be periods of excess nuclear capacity and therefore incentive to exercise short-run market power. In this case VPP contracts might still be useful.

\subsection{Tax expropriation}

In Sweden, the nuclear tax and the property taxes on hydropower plants have increased several times in recent years. In 2000, the nuclear tax shifted from a production tax to a tax on installed capacity. As the nuclear tax no longer imposes any short-run distortions in the economy, it has become politically more tempting to increase it. The latest increase took place 
in 2008. In the long run, however, tax expropriation is likely to drive private investors out of the market and may lead to underinvestment.

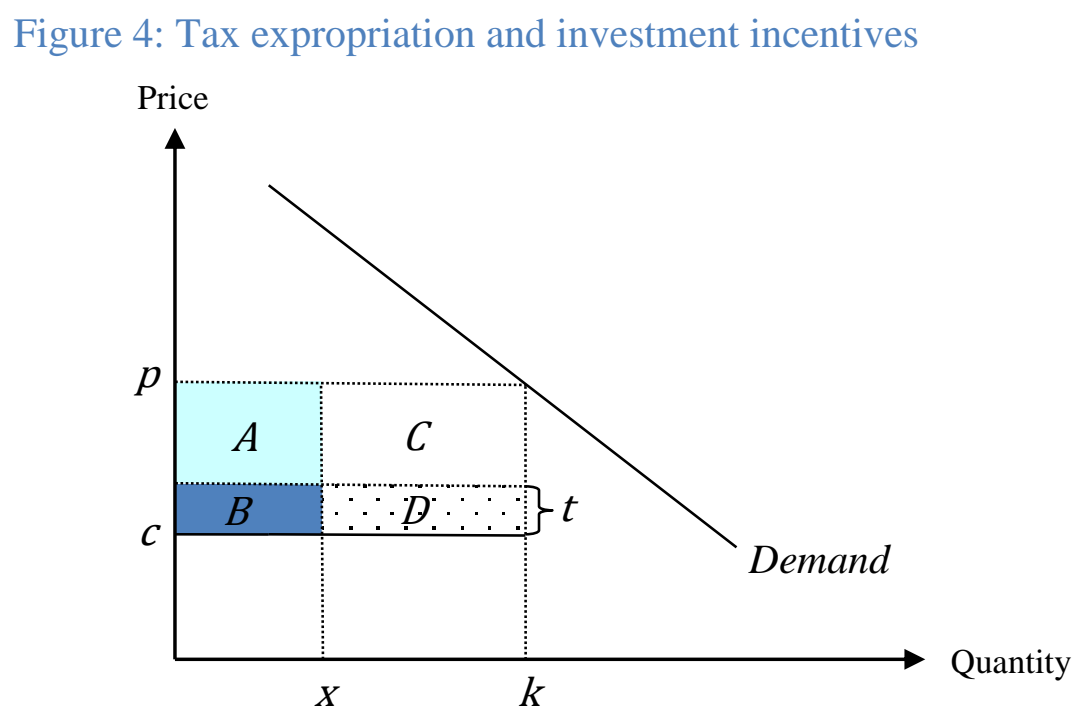

Figure 4 illustrates the problem of tax expropriation. ${ }^{17}$ Installed nuclear capacity is given by $k$ in the figure. Nuclear power is produced at constant (short-run) marginal cost $c$. Demand is so high that producing at full capacity $k$ for the price $p$ is profitable. Nuclear operating profit is then given by $(p-c-t) k$, where $t$ is the nuclear capacity tax. Suppose the government owns a share $x / k$ of installed capacity $k$, the rest being owned by private investors. Independently of the nuclear tax, direct ownership yields government profit $A+B=$ $(p-c) x$. In addition, the government collects $D=t(k-x)$ in tax revenues from the private owners. The white area $C=(p-c-t)(k-x)$ constitutes the operating profit of the private owners. The capital cost being sunk, the government can raise the nuclear tax ex post at the expense of private owners until $t=p-c$ (so that $C=0$ ) and thereby collect the entire operating profit $(p-c) k$. Of course, a zero expected operating profit does not cover the capital cost of the private investment and a private investor anticipating such a severe expropriation would stay out of the market. The return on the government investment, on the other hand, remains unaffected by tax expropriation because nuclear taxes and operating revenues are equivalent. Thus, tax expropriation leads to crowding-out of private investment to the benefit of government investment.

\footnotetext{
${ }^{17}$ We restrict attention to nuclear capacity taxes. Himpens et al. (2011) analyze commitment problems in relation to nuclear production taxes. They propose nuclear capacity auctions, too, but as a means to raise government revenue beyond what is possible by production taxes alone.
} 
State ownership might be a prerequisite for investment in industries where tax expropriation is expected to constitute a major problem. Although state ownership is not bad per se, it would be useful to find mechanisms promoting private investment despite the risk of tax expropriation. A diversified ownership structure is desirable, not least to reduce market power. Long-term supply contracts constitute one such potential mechanism.

Revisit Figure 4 and assume that private investors plan to build a nuclear plant with capacity $k$. Suppose these investors, prior to building the power plant, sell long-term supply contracts for $x$ MWh electricity in the form of options with strike price $c$ per MWh. The revenue from selling the nuclear contracts can be used to finance the construction of the nuclear power plant, reducing capital costs. When the plant becomes operational it makes zero operating profit on the $x \mathrm{MWh}$ of energy sold at marginal $\operatorname{cost} c$. The operating profit available for tax expropriation from the nuclear owners then falls from $(p-c) k$ to $(p-c)(k-x)$. In the limit when the supply contracts cover the entire production $k$, no operating profit remains for expropriation. The value to the investors of selling the contracts depends on the selling price. If the state can equally well expropriate the contract owners, the ex post profit tax equals the profit margin $p-c$ and the selling price falls to zero as the long-term contracts become worthless to the buyers. With full tax expropriation of buyers, long-term supply contracts cannot overcome tax expropriation of investors. In many cases, buyers would be energy intensive industries with a desire to hedge their electricity consumption. Tax expropriation would be limited insofar expropriating large industrial consumers rather than generating companies is more difficult from a political perspective. In addition, long-term supply contracts represent only one of several instruments consumers can use to hedge their electricity consumption. Tax expropriation would be further limited if, for legal reasons, it is difficult to tax discriminate between different financial instruments. In the limit when tax expropriation of buyers becomes impossible, the selling price is $p-c$ per MWh. In this case, the investor can fully avoid tax expropriation by selling the entire production up front.

In the long run, tax expropriation constitutes a problem for the government itself. The shortrun gain of expropriating installed production capacity can be dominated by the long-run cost of foregone investment. Thus it is in the self-interest of the government to create mechanisms that are robust to tax expropriation. Long-term supply contracts constitute an example of one such possible instrument. More generally, a transparent and predictable energy policy is of vital importance for a healthy investment climate. This is especially true for the highly 
concentrated electricity markets. Political uncertainty presents large companies with an opportunity to exercise market power under the pretext that political risk renders investments unprofitable. A transparent and predictable energy policy would simplify market monitoring of the market participants.

\subsection{Other issues}

We mainly consider the problem of auctioning off a license to build a homogeneous nuclear reactor with fixed capacity and known marginal production cost. Typically, nuclear reactors differ from one another in terms of reactor design, capacity, safety systems, and so forth. Most likely, the bidders will compete in differentiated reactors. One approach to selecting among different designs is to construct a set of minimum standards and award the license to the highest bidder with a project that fulfills the standard. A winner who subsequently fails to live up to these standards is penalized. This is not the best way to set up an auction, as the following example demonstrates. There are two projects, one of which by far dominates the other in all dimensions but one. The superior project falls short of the capacity requirement by $\varepsilon$, whereas the inferior project precisely meets the capacity- and all other requirements. Both bidders are willing to pay the same license fee. The superior project is disapproved and the license awarded to the inferior project by strict application of the standard, although this cannot possibly be socially optimal. In an alternative auction the seller scores each project based on a ranking of the different attributes of the objects and awards the license to the bidder with the highest score relative to the price. Scoring auctions typically outperform other differentiated goods auction formats because the various attributes are weighted against one another in a more efficient manner (Asker and Cantillon, 2008). The main challenge lies in constructing a scoring function which appropriately accounts for the relative importance of the different attributes. Naturally, the task becomes significantly easier if the seller chooses among mature designs with established performance records and predictable construction times instead of opting for cutting-edge nuclear technology.

Participation in the auction is likely to be costly, even for non-winning bidders. Participation costs reduce the attractiveness of the auction, the number of bidders, and thereby the auction's performance. First, participation costs may deter efficient bidders from participating in the auction, particularly so if the more efficient bidders have higher participation costs. This concern could be relevant for nuclear capacity auctions where incumbents may have lower participation costs than potential entrants due to superior knowledge about relevant market 
characteristics, regulations and so on. Second, large participation costs may deter too many potential bidders, leading to underinvestment. Third, the participation costs are duplicated, the larger the number of bidders. Despite these problems, nuclear capacity auctions still have many desirable properties, particularly so if the participation costs are not too different across potential bidders; then inefficient bidders are usually deterred first and the likelihood that the bidder with the lowest cost wins the license is at least not reduced (Tan and Yilankaya, 2006). Nonetheless, reducing these costs is desirable. For example, by specifying in advance and as precisely as possible the rules of the auction, the conditions for participating and so on, the seller reduces all bidders' participation costs, perhaps even substantially so. As a side effect, the seller thereby also reduces the differences in participation costs across firms, which further ought to increase the auction's performance.

So far we have considered the problem of auctioning a license to build a single reactor. In Sweden, there might be as much as ten licenses for sale to replace the current reactors. In a multi-unit auction questions arise whether to bundle the licenses together or sell them separately, and whether to sell them simultaneously or in a sequential auction. The answer depends on the purpose of the auction. If the goal was to maximize expected auction revenue, it would be a good idea to bundle licenses together. ${ }^{18}$ Consider Figure 3 and assume that there are no nuclear reactors from the outset. Two licenses are up for sale, each one for a nuclear reactor of size $k_{n} / 2$. A bidder who wins both licenses gains monopoly power and earns $\pi^{m}$. Two bidders who win one license each earn a total of $\pi^{d}<\pi^{m}$. Thus, the total valuation of the two licenses is higher if they are bundled together. Fostering a concentrated market structure with the intention of maximizing seller revenue hardly constitutes a socially optimal policy. On the contrary, one of the goals would be to reduce market concentration through entry. The likelihood of entry is maximized by selling each reactor separately. In the special case when there are more reactors than bidders and every bidder demands at most one reactor, there is no bidding competition at all: every bidder wins one license each and pays the reserve price. In this case the auction generates no revenues at all - unless the reserve price is positive. The number of serious bidders will probably be quite small. On the other hand, bidders may be interested in more than one reactor, so total demand may be larger than total supply. Nonetheless, it may be necessary to bundle reactors to create serious bidding competition. Building the very first reactor of a novel design usually is very costly, whereas

\footnotetext{
${ }^{18}$ Maximization of expected seller revenue is the standard objective function in the literature on optimal auction design.
} 
the subsequent ones are substantially cheaper. Owing to falling average construction cost, bundling reactors can be a good idea when learning curves are important. Whenever bundling could be economical, it is probably wise to allow bidders to bid on multiple reactors as well as single units in a so-called combinatorial auction. This maximizes the flexibility of the auction design while allowing bidders to harvest returns to scale.

The realized value of the investment equals the (discounted) operating profit less the investment cost, both of which are uncertain at the time of the auction. Because of its size, it is important to estimate the value of the investment as correctly as possible. Bidders who pay too much for the license run the risk of not being able to finance the reactor itself, or the project will be delayed until the firm has recovered financially. Investment costs probably differ a lot across bidders, profit streams depend much less on the identity of the winner provided all bidders are price takers and would build reactors similar to one another in terms of operating costs and capacity, and they run the plants equally efficiently. The investment thus contains a significant common value component - the expected operating profit. Because the bidders are likely to assess expected profitability similarly, sequential auctions possess a price discovery feature which renders it more easy to judge the profitability of future investments. For practical and economic purposes, sequential auctions are likely to be optimal rather than auctioning off all licenses in one go.

The discussion of the value of nuclear power has evolved around the demand for electricity relative to the cost of producing it. Nuclear power is associated with potentially devastating environmental costs, not least witnessed by the recent Fukushima meltdown. The validity of the above analysis depends on the extent to which the owners of nuclear power internalize its full social cost in their investment and production decisions. Swedish nuclear power plants pay a production tax and plant specific fees to cover the storage cost of nuclear waste. The production tax is captured in marginal production cost. The Swedish Parliament is currently processing a law which will demand full liability for all costs arising from nuclear accidents. In practice, liability will be bounded by the bankruptcy constraint or the ability to reinsure the accident risk in the market. Liability will be captured in the capital costs of the investment. Note finally that new Swedish nuclear reactors only are relevant as replacements for old ones. If recent generations of reactors are perceived as safer than older ones, the insurance cost may actually fall. 
Constructing and operating nuclear plants represent significant investments on a national scale and are so demanding in terms of know-how, capital and labour that they are likely to have significant effects on the other parts of the economy. An investor concerned with the profitability of the project is not likely to be concerned with such general equilibrium effects which could be beneficial to the rest of the economy (positive technological spillovers, industrial development) or negative (increased wage cost). The problem of properly accounting for economy-wide effects of nuclear investments is general and stretches beyond the choice of auction format. The purpose of the auction is constrained to eliciting information about the costs and benefits of producing and consuming nuclear electricity.

\section{Conclusion}

We propose nuclear capacity auctions as a means to improve investment incentives. The aim of the auction is to introduce competitive pressure in the investment decision and to single out the most appropriate firm for the task, conditional on investment being socially optimal.

Colombia and New England currently operate capacity auctions with the purpose of ensuring adequate reserve capacity for periods of scarcity (Ausubel and Cramton, 2010a). The spot market for electricity is thought to provide insufficient investment incentives because average capacity utilization of production reserves is low, and price ceilings prevent spot prices from increasing to the levels necessary to render investments profitable. Neither of these two problems are present when it comes to nuclear capacity. Nuclear marginal production cost is so low that the reactors would produce at full capacity most of the time, and new nuclear power would be profitable at prices way below the ceiling. Instead, investment incentives are distorted because of market power and entry barriers.

Nuclear capacity auctions would be sizeable; alone the construction cost of a modern nuclear reactor exceeds 3 billion Euros. Just because the values at stake are high, this does not mean that the licenses could not or should not be auctioned off. The highly successful auction of radio spectrum in the UK in 2000 cost the bidders more than 34 billion dollars - just for the licenses (Klemperer, 2004). This spectrum auction provides an interesting reference also because of its objectives, which were to ( $i$ ) assign spectrum efficiently; (ii) promote competition; (iii) realize the full economic value of the spectrum. Many of the design issues pertaining to spectrum auctions - how to attract bidders, how to avoid collusion - are relevant also to nuclear capacity auctions. This paper has sketched some desirable properties of 
nuclear capacity auctions. More work needs to be done in pinning down the specific details of the auction design.

\section{Acknowledgements}

This research was financed within the IFN research program "The Economics of Electricity Markets".

\section{References}

Asker, John, and Estelle Cantillon (2008): Properties of scoring auctions, RAND Journal of Economics 39, 69-85.

Ausubel, Lawrence M. and Peter Cramton (2010a): Using forward markets to improve electricity market design, Utilities Policy 18, 195-200.

Ausubel, Lawrence M. and Peter Cramton (2010b): Virtual power plant auctions, Utilities Policy 18, 201-206.

Borenstein, Severin, Jim Bushnell and Frank A. Wolak (2002.): Measuring market inefficiencies in California's restructured wholesale electricity market, American Economic Review 92, 1376-1405.

Bulow, Jeremy, and Paul Klemperer (1996): Auctions versus negotiations, American Economic Review 86, 180-194.

Fridolfsson, Sven-Olof and Thomas Tangerås (2009): Market power in the Nordic electricity wholesale market: A survey of the empirical evidence, Energy Policy 37, 3681-3692.

Himpens, Pieter, Joris Morbee and Stef Proost (2011): Taxation of nuclear rents: Benefits, drawbacks and alternatives, Center for Economics Studies DPS 11.16, KU Leuven.

Joskow, Paul (2008): Lessons learned from electricity market liberalization, Energy Journal 29, 9-42.

Jehiel, Philippe, Benny Moldovanu and Ennio Stacchetti (1996): How (not) to sell nuclear weapons, American Economic Review 86, 814-829.

Klemperer, Paul (2004): Auctions: Theory and Practice, Princeton, NJ: Princeton University Press.

Milgrom, Paul (2004): Putting Auction Theory to Work, New York, NY: Cambridge University Press.

Myerson, Roger (1981): Optimal auction design, Mathematics of Operations Research 6, 5873.

NordREG (2011): Nordic market report, Report 3/2011. 
Swede Energy (2011): The electricity year 2010, Retrieved from www.svenskenergi.se/sv/InEnglish/The-Electricity-Year/ January 31, 2012.

Tan, Guofu and OkanYilankaya (2006): Equilibria in second price auctions with participation costs, Journal of Economic Theory, 130, 205-219.

Wolfram, Catherine (1999): Measuring duopoly power in the British electricity spot market, American Economic Review 89, 805-826. 